\title{
Avaliação por diferentes olhares: fatores que explicam o sucesso de escola carioca em área de risco
}

Douglas Teixeira Cardelli*

Ligia Gomes Elliot**

\section{Resumo}

A proposta ora formulada é um estudo avaliativo das relações estabelecidas entre alunos, gestores, comunidade do entorno, familiares, professores e técnicos pedagógicos, de uma escola pública da região metropolitana do Rio de Janeiro. Inserida em uma área de risco, a escola vem apresentando, ao longo dos anos, resultados positivos em suas avaliações, o que se contrapõe a alguns paradigmas de fracasso escolar. No estudo, foram entrevistados alunos, gestores, professores, especialistas pedagógicos da escola, o que permitiu a obtenção de informações necessárias à avaliação do contexto escolar em todas as suas dimensões para o desenvolvimento de práticas pedagógicas de sucesso. Os resultados da avaliação refletem que o bom desempenho dessa unidade escolar está associado, de maneira geral, a fatores como: participação da família e da comunidade na vida escolar, alta expectativa do professor com relação à aprendizagem dos alunos, participação ativa da equipe gestora, atenção dada às atividades realizadas no espaço escolar; realização de trabalho de casa pelos alunos; rede física conservada e acolhedora; proposta pedagógica definida com práticas contextualizadas e significativas, utilização de material de apoio pedagógico adequado.

Palavras-chave: Avaliação. Ensino Fundamental. Práticas pedagógicas. Fatores de sucesso escolar.

\section{Evaluation for different looks: factors that explain the success of a school in a risky zone of Rio de Janeiro Abstract}

This paper reports an evaluative study of relationships between students, administrators, the surrounding community, family, teachers of a public school in a danger zone of the metropolitan region of Rio de Janeiro. Over the years, this school has shown positive results in their evaluations, which goes against some paradigms of school failure.

\footnotetext{
* Mestre em Avaliação, Fundação Cesgranrio; Professor de Língua Portuguesa do Município do Rio de Janeiro e Disciplinas Pedagógicas do Instituto Nacional de Surdos (INES). E-mail: dtcardelli@globo.com.

** PhD em Educação/Avaliação, UCLA; Coordenadora e docente do Curso de Mestrado Profissional em Avaliação, Fundação Cesgranrio. E-mail: ligia@cesgranrio.org.br.
} 
In this study students, teachers and educational specialists were interviewed, which allowed to obtain necessary information for evaluating the school context in all its dimensions for the development of successful teaching practices. The results of the evaluation reflect that the good performance of this school is associated, in general, to factors such as family and community participation in school life, teacher's high expectation with respect to students' learning, active participation of the management team, attention given to classroom activities; home work; good conditions of the school building; pedagogical proposal set with contextualized and meaningful practice, and use of appropriate pedagogical support materials.

Keywords: Assessment. Basic education. Pedagogical practices. Factors of school success.

\section{Evaluación de miradas diferentes: factores que explican el éxito de una escuela en la zona de riesgo en Rio de Janeiro}

\section{Resumen}

Este artículo es un estudio de evaluación de las relaciones entre los estudiantes, los administradores, la comunidad que los rodea, la familia, los maestros de una escuela pública en una zona peligrosa de la región metropolitana de Río de Janeiro. Esta escuela ha mostrado resultados positivos en sus evaluaciones, lo cual se opone a algunos paradigmas de fracaso escolar. En este trabajo se entrevistaron estudiantes, profesores y especialistas en educación, lo que permitió obtener informaciones necesarias para evaluar el contexto escolar en todas sus dimensiones para efecto del desarrollo de las prácticas pedagógicas de enseñanza exitosa. Los resultados de la evaluación reflejan que el buen desempeño de la escuela está asociado, en general, a factores tales como: participación de la familia y la comunidad en la vida escolar, alta expectativa del maestro con respecto al aprendizaje de los estudiantes, participación activa del equipo gestor, atención ofrecida a las actividades realizadas en el aula; deberes escolares hechos en casa; buenas condiciones físicas de la escuela y ambiente hospitalario; propuesta pedagógica con práctica contextualizada y significativa, uso de material de apoyo pedagógico adecuado, entre otros.

Palabras clave: Evaluación. Enseñanza básica. Prácticas pedagógicas. Factores de éxito escolar.

\section{O Sistema Municipal de Ensino do Rio de Janeiro e o processo avaliativo}

As mudanças que vêm ocorrendo na sociedade, especialmente nas últimas décadas, têm levado à reflexão sobre o papel das instituiç̧ões de ensino no processo 
de socialização dos indivíduos, de que forma vêm contribuindo na sua preparação para enfrentar os desafios que são impostos no dia-a-dia, sejam nas relações profissionais ou pessoais. Supor essa questão reporta à escola em si, ao sentido dado à aprendizagem dos alunos e, especialmente, à forma como esta última vem conduzindo seus processos internos e externos de avaliação, bem como as relações que dentro dela ocorrem, nos modelos de práticas avaliativas que adotam.

A respeito dos processos de avaliação, Hoffmann (2003, p. 13-14) chama atenção para críticas existentes:

\begin{abstract}
A verdade é que há um sério descrédito em relação às escolas inovadoras e o sistema de avaliação é um dos focos principais de crítica da sociedade, uma vez que se constitui em comportamento decisivo na questão resultados, ou seja, produto obtido, em educação. Enfim, a crença popular é que os professores tendem a ser menos exigentes do que tradicionalmente e que as escolas não oferecem o ensino competente à semelhança das antigas gerações.
\end{abstract}

As unidades escolares, independente do nivel de ensino e da esfera a qual pertencem, têm seu papel definido na Lei de Diretrizes e Bases da Educação Nacional (LDBEN) no. 9.394 (BRASIL, 1996). A LDBEN (BRASIL, 1996, Art. 9º inciso VI) estabelece que a União incumbir-se-á de: assegurar processo nacional de avaliação do rendimento escolar no Ensino Fundamental, Médio e Superior, em colaboração com os sistemas de ensino, objetivando a definição de prioridades e a melhoria da qualidade do ensino.

Caberá às escolas definirem um modelo de avaliação que Ihes possibilite cumprir não apenas o preceito legal, mas exercerem seu papel de geradoras, sistematizadoras e socializadoras do saber. Sem dúvida, esse dispositivo tem requerido não só mudança das práticas pedagógicas e de avaliação, mas especialmente, mudança no enfoque teórico e no conteúdo destas em nível mais profundo, com a mudança da própria natureza e da função social da escola.

No município do Rio de Janeiro, a Secretaria Municipal de Educação do Rio de Janeiro (SME-RJ) orienta o trabalho pedagógico, fornecendo às unidades escolares, Orientações Curriculares e Cadernos de Apoio Pedagógico que funcionam como norteadores que auxiliam as instituições na elaboração, desenvolvimento e avaliação das práticas pedagógicas dos professores, e possibilitam a construção de uma autonomia essencial para implementação do projeto político-pedagógico de cada escola.

Os resultados apresentados pelas escolas municipais no Rio de Janeiro, inseridas em áreas de risco, têm mostrado o quanto vários mitos presentes no imaginário dos envolvidos no processo pedagógico contribuem para que, ainda, hoje, as crianças oriundas das classes populares fracassem, continuando na posição de oprimidas. 
No entanto, existem escolas com resultados favoráveis, mas isso ainda ocorre de forma pouco expressiva. Assim, um estudo avaliativo sobre uma escola localizada em área de risco, que apresentasse alto desempenho, de modo a fornecer dados sobre essa relação se configura como oportuno e necessário.

\section{Objetivo e justificativa do estudo}

No Rio de Janeiro, os resultados obtidos pelos alunos do $5^{\circ}$ ano do Ensino Fundamental (EF) da Escola Municipal (EM) Santos Anjos, nas avaliações nacionais e estaduais, apesar de estar inserida em área de risco, mostram o bom desempenho dos alunos. Assim, o presente estudo teve como objetivo avaliar que fatores levam essa escola a apresentar tais resultados.

Houve a preocupação com os fatores que, possivelmente, explicam o sucesso da escola carioca em área de risco, considerando, então, o contexto familiar dos alunos, 0 ambiente escolar, a atuação dos professores e o envolvimento dos alunos em práticas pedagógicas. Tais fatores encontram apoio em pesquisas empíricas, citadas na literatura internacional (BROOKOVER, 1979; HILL; ROWE; JONES, 1995; SCHEERENS; BOSKER, 1997; SCHEERENS; BRUMMELHIUS, 1996). Ao investigar vários desses fatores numa realidade diversa, ou seja, de escola carioca em área de risco, o presente estudo se justifica ao permitir estabelecer relações com as pesquisas internacionais.

Ao tratar desses fatores, a avaliação poderá servir como modelo ou base de reflexão para gestores, professores, alunos, pais e demais envolvidos da comunidade escolar. Os benefícios futuros oriundos da presente avaliação poderão inspirar práticas pedagógicas de outras unidades inseridas nesse tipo de comunidade.

\section{A EM Santos Anjos e seu contexto}

A EM Santos Anjos fica localizada em um conjunto habitacional, no Leblon, bairro da zona sul da cidade do Rio de Janeiro. 0 conjunto é composto por 10 prédios, com um total de 945 apartamentos e mais de 4.000 moradores. Esse conjunto foi inaugurado na década de 50, com o objetivo de fazer dali uma espécie de plano piloto para acabar, em 10 anos, com as 150 favelas existentes na cidade. Hoje, se veem paredes descascadas; escadas mal-cuidadas; varais descoordenados; janelas abertas por onde se pode notar os apartamentos pobres, e aquela gente simples: um típico e dramático exemplo dos gigantescos e tristes contrastes socioeconômicos da cidade do Rio de Janeiro.

A EM Santos Anjos atende jovens oriundos da comunidade da Cruzada de São Sebastião, do Vidigal, Rocinha, Chácara do Céu, Leblon, Ipanema. Possui 531 alunos matriculados, distribuídos da Educação Infantil ao $5^{\circ}$ ano do EF, em horário parcial. Há duas turmas de $5^{\circ}$ ano com 34 e 36 alunos, respectivamente, e o índice de reprovação foi baixo em 2009. A reprovação é comentada por Becker (2010): 
Um sistema educacional que reprova sistematicamente seus estudantes fazendo com que grande parte deles abandone a escola antes do tempo não é desejável. Tampouco pode ser considerado satisfatório um sistema que aprove seus alunos ao mesmo tempo em que permite que estes saiam da escola sem ter adquirido o nível de conhecimento apropriado.

A despeito de estar situada em área de risco, a escola tem alcançado bons resultados expressos pelo Índice de Desenvolvimento da Educação Básica (IDEB), que varia de zero a $10^{1}$ (Tabela 1).

Tabela 1 - IDEB e Metas Projetadas da EM Santos Anjos

\begin{tabular}{c|c|c|c|c|c|c|c|c|c|c|c}
\hline \multirow{2}{*}{$\begin{array}{c}\text { Ensino } \\
\text { Fundamental }\end{array}$} & \multicolumn{3}{|c|}{ IDEB } & \multicolumn{1}{c}{ Metas Projetadas } \\
\cline { 2 - 13 } & 2005 & 2007 & 2009 & 2007 & 2009 & 2011 & 2013 & 2015 & 2017 & 2019 & 2021 \\
\hline Anos Iniciais & 5,6 & 6,0 & 6,6 & 5,7 & 6,0 & 6,3 & 6,6 & 6,8 & 7,0 & 7,2 & 7,4 \\
\hline
\end{tabular}

Fonte: Adaptado do INEP (2009).

Considerando o IDEB observado em 2005, 2007 e 2009 e as metas projetadas para a EM Santos Anjos, nota-se que os resultados alcançados estão acima da média do município $(5,1)$ e da média nacional $(4,6)$. 0 resultado de 2009 já atingiu a meta estabelecida para o ano de 2013, o que é notável.

Tabela 2 - Resultados do $5^{\circ}$ ano do EF da EM Santos Anjos na Prova Brasil - 2005, 2007 e 2009

\begin{tabular}{c|c|c|c|c|c|c}
\hline \multirow{2}{*}{ Unidades } & \multicolumn{2}{|c|}{2005} & \multicolumn{2}{c|}{2007} & \multicolumn{2}{c}{2009} \\
\cline { 2 - 7 } & Português & Matemática & Português & Matemática & Português & Matemática \\
\hline Brasil & 172,91 & 179,98 & 171,40 & 189,14 & 184,30 & 204,30 \\
\hline Estado RJ & 178,40 & 184,44 & 176,62 & 192,79 & 192,11 & 210,83 \\
\hline Município RJ & 183,35 & 190,64 & 178,02 & 194,10 & 198,43 & 218,64 \\
\hline Escola & 207,91 & 226,35 & 215,61 & 229,51 & 226,20 & 246,40 \\
\hline
\end{tabular}

Fonte: Adaptado do INEP (2009).

Pode-se perceber, também, o avanço nos resultados dos alunos do $5^{\circ}$ ano em Língua Portuguesa e em Matemática, por meio dos resultados das últimas edições da Prova Brasil (Tabela 2).

10 IDEB é calculado com base na taxa média de aprovação e no desempenho dos alunos do $5^{\circ}$ e do $9^{\circ}$ ano do Ensino Fundamental e $3^{\circ}$ ano do Ensino Médio, no Sistema Nacional de Avaliação da Educação Básica (SAEB). O SAEB tem por objetivo avaliar a qualidade do ensino oferecido pelo sistema educacional brasileiro, a partir de testes padronizados e questionários socioeconômicos. Quanto maior for a nota no teste nacional e quanto menos repetências e abandonos registrar, a classificação da escola será melhor. 
Tabela 3 - Aprovação dos alunos do $5^{\circ}$ ano do EF da EM Santos Anjos

\begin{tabular}{l|c|c}
\hline \multicolumn{1}{c|}{ Niveis } & 2008 & 2009 \\
\hline Rede Municipal de Ensino do Rio de Janeiro & $87 \%$ & $81 \%$ \\
\hline $2^{\text {a Coordenadoria Regional de Educação }}$ & $84 \%$ & $81 \%$ \\
\hline Unidade Escolar & $90 \%$ & $92 \%$ \\
\hline
\end{tabular}

Fonte: Adaptado do Sistema de Controle Acadêmico SME-RJ (2009).

Outro aspecto relevante para que se considerasse a prática pedagógica como satisfatória foi o resultado final do desempenho escolar, apresentado nos anos de 2008 e 2009 em relação à Rede Municipal, à Coordenadoria Regional de Educação e à própria Unidade Escolar, de acordo com dados da Tabela 3.

A concepção de avaliação da escola corrobora o que destaca Becker (2010, p.3):

[...] a avaliação não é um fim em si mesmo, mas um instrumento que deve ser utilizado para corrigir rumos e pensar o futuro. É crucial assegurar que, juntamente com as informações que a avaliação fornece, sejam criados e utilizados instrumentos que contribuam substancialmente para a solução dos sérios problemas sociais que afetam a população em idade escolar.

\section{Procedimentos metodológicos}

São aqui apresentados a abordagem utilizada, os instrumentos elaborados, validados e aplicados, a descrição da coleta e do tratamento dos dados e os critérios de julgamento dos resultados do estudo avaliativo.

\section{Abordagem da avaliação}

A escolha da abordagem avaliativa a ser utilizada em uma avaliação é sempre muito desafiadora para os avaliadores. No caso desse estudo, foi adotado, dentre outros, o modelo de avaliação centrado nos participantes, como se verifica em Worthen, Sanders e Fitzpatrick (2004, p.224): "a avaliação centrada nos participantes abrange uma grande variedade de propostas mais especificas que, em termos gerais, podem ser reunidas por sua aceitação da filosofia intuicionistapluralista da avaliação". A abordagem permite que a pluralidade de julgamentos os participantes faça parte do estudo avaliativo.

\section{Categorias, indicadores e padrões}

A partir do propósito do presente estudo, foram estabelecidos indicadores objetivos e comuns para avaliação, e organizados em diferentes categorias. Esses indicadores foram considerados essenciais e necessários para que se compreendam a influência 
do contexto familiar, a organização e estruturação do ambiente escolar, a atuação do corpo docente e a participação dos alunos nas práticas pedagógicas, de modo a se perceber o envolvimento dos sujeitos participantes desse processo (Quadros 1, 2 e 3 ).

Quadro 1 - Categorias contexto familiar e contexto escolar, indicadores e padrões

\begin{tabular}{|l|l|l|}
\hline \multicolumn{1}{|c|}{ Categoria } & \multicolumn{1}{|c|}{ Indicador } & \multicolumn{1}{c|}{ Padrão } \\
\hline $\begin{array}{l}\text { Contexto } \\
\text { Familiar }\end{array}$ & $\begin{array}{l}\text { Acompanhamento na } \\
\text { vida escolar do aluno }\end{array}$ & $\begin{array}{l}\text { A colaboração dos pais/responsáveis na } \\
\text { realização das atividades de dever de } \\
\text { casa, reforço e atividades do cotidiano } \\
\text { escolar. }\end{array}$ \\
\hline Contexto Escolar & $\begin{array}{l}\text { Organização do } \\
\text { ambiente escolar }\end{array}$ & $\begin{array}{l}\text { 0 espaço fisico favorável possibilita a } \\
\text { aproximação: com a teoria pedagógica; } \\
\text { com a linha metodológica; com a } \\
\text { proposta politica de educação assumida } \\
\text { pela Unidade Escolar. }\end{array}$ \\
\cline { 2 - 3 } & $\begin{array}{l}\text { Acesso e permanência no } \\
\text { espaço escolar }\end{array}$ & $\begin{array}{l}\text { As atividades pedagógicas reduzem o } \\
\text { abandono e evasão. }\end{array}$ \\
\cline { 2 - 3 } & $\begin{array}{l}\text { Relação entre o tamanho da } \\
\text { Unidade Escolar e o } \\
\text { desempenho }\end{array}$ & $\begin{array}{l}\text { A estrutura da Unidade Escolar por } \\
\text { segmentos. }\end{array}$ \\
\cline { 2 - 3 } & $\begin{array}{l}\text { Relação entre o tamanho das } \\
\text { turmas e o desempenho }\end{array}$ & $\begin{array}{l}\text { Os grupamentos da Educação Infantil } \\
\text { ao 50 ano do EF estão formados de } \\
\text { acordo com a Portaria E/SUBE/CED de } \\
\text { 05/11/2009 }\end{array}$ \\
\hline
\end{tabular}

Quadro 2 - Categoria atuação do corpo docente, indicadores e padrões

\begin{tabular}{|c|c|c|}
\hline Categoria & Indicador & Padrão \\
\hline \multirow{5}{*}{$\begin{array}{l}\text { Atuação do } \\
\text { Corpo } \\
\text { Docente }\end{array}$} & Gênero & Distribuição do gênero masculino e feminino. \\
\hline & Faixa etária & Distribuição da faixa etária \\
\hline & $\begin{array}{l}\text { Experiência } \\
\text { profissional }\end{array}$ & Maturidade profissional/nivel de escolaridade \\
\hline & $\begin{array}{l}\text { Qualidade do } \\
\text { planejamento do } \\
\text { professor }\end{array}$ & $\begin{array}{l}\text { As práticas pedagógicas estão adequadas às } \\
\text { necessidades da clientela de acordo com o proposto } \\
\text { na tendência pedagógica crítico-social dos conteúdos. }\end{array}$ \\
\hline & $\begin{array}{l}\text { Adequação dos } \\
\text { conteúdos aos } \\
\text { objetivos de ensino }\end{array}$ & $\begin{array}{l}\text { Objetivos relacionados com os conteúdos a partir do } \\
\text { Projeto Político Pedagógico. }\end{array}$ \\
\hline
\end{tabular}


(Continuação)

\begin{tabular}{|c|c|c|}
\hline & $\begin{array}{l}\text { Ação educativa } \\
\text { comprometida com } \\
\text { a construção de uma } \\
\text { sociedade justa e } \\
\text { solidária }\end{array}$ & $\begin{array}{l}\text { Planejamento do trabalho pedagógico a partir da ótica } \\
\text { dos excluídos sociais. } 0 \text { diálogo como ferramenta de } \\
\text { participação e inclusão social. }\end{array}$ \\
\hline & Prática Pedagógica & $\begin{array}{l}\text { Práticas Pedagógicas que possibilitem a aprendizagem } \\
\text { significativa. }\end{array}$ \\
\hline \multirow{2}{*}{$\begin{array}{l}\text { Atuação do } \\
\text { Corpo } \\
\text { Docente }\end{array}$} & $\begin{array}{l}\text { Qualidade dos materiais } \\
\text { pedagógicos utilizados } \\
\text { pelos docentes }\end{array}$ & $\begin{array}{l}\text { Os materiais pedagógicos selecionados possibilitam a } \\
\text { aproximação com: } \\
\text { a teoria pedagógica; } \\
\text { a linha metodológica; } \\
\text { a proposta política da educação assumida pela Unidade } \\
\text { Escolar. }\end{array}$ \\
\hline & $\begin{array}{l}\text { Avaliação do ensino- } \\
\text { aprendizagem }\end{array}$ & $\begin{array}{l}\text { Identificação da avaliação a partir do que foi } \\
\text { estabelecido no planejamento educacional e no Projeto } \\
\text { Político Pedagógico. } \\
\text { Contemplação da ótica dos excluídos sociais. } \\
\text { Atendimento LDBEN 9.394/96 Artigos 90 Inciso VI e } \\
87 \text { Inciso IV. } \\
\text { Realização de prática dialógica. }\end{array}$ \\
\hline
\end{tabular}

Quadro 3 - Categoria atuação do corpo discente, indicadores e padrões

\begin{tabular}{|c|c|c|}
\hline Categoria & Indicador & Padrão \\
\hline \multirow{5}{*}{$\begin{array}{l}\text { Atuação do } \\
\text { Corpo } \\
\text { Discente }\end{array}$} & Gênero & Distribuição de gênero (masculino e feminino) \\
\hline & $\begin{array}{l}\text { Experiências trazidas } \\
\text { pelos alunos }\end{array}$ & $\begin{array}{l}\text { Realização de prática de inclusão social. } \\
\text { Integração com situações de construção de } \\
\text { conhecimento. }\end{array}$ \\
\hline & $\begin{array}{l}\text { Qualidade das situações } \\
\text { de aprendizagem }\end{array}$ & $\begin{array}{l}\text { Utilização da Sala de Leitura e Sala de Informática. } \\
\text { Realização de atividades lúdicas e recreativas. }\end{array}$ \\
\hline & $\begin{array}{l}\text { Relação professor/ } \\
\text { aluno }\end{array}$ & $\begin{array}{l}\text { Prática dialógica/ } \\
\text { Aprendizagem significativa }\end{array}$ \\
\hline & $\begin{array}{l}\text { Envolvimento no } \\
\text { coletivo escolar }\end{array}$ & $\begin{array}{l}\text { Engajamento em projetos e ações desenvolvidas na } \\
\text { escola. }\end{array}$ \\
\hline
\end{tabular}




\section{Seleção dos instrumentos de coleta de dados}

A estruturação dos instrumentos de avaliação é uma das etapas essenciais mais importantes do estudo avaliativo. Para Worthen, Sanders e Fitzpatrick (2004, p.467) "[...] nenhum avaliador que se preze pensaria em fazer julgamentos avaliatórios sem primeiro dispor de uma sólida base de evidências". Tais evidências, considerando a amplitude dos dados e das informações, são conseguidas a partir de instrumentos que contemplem dados de natureza qualitativa e quantitativa.

Para coletar as informações do corpo docente, foi usado o questionário aplicado pelo INEP, na Prova Brasil de 2005 (INEP, 2009), com 45 questões fechadas. 0 questionário para alunos foi adaptado do aplicado na Prova Brasil. Foram selecionadas 40 questões fechadas, relacionadas às categorias contexto familiar, contexto escolar, atuação do corpo docente e atuação do corpo discente.

Ambos os questionários tinham a finalidade de verificar o que pensavam, como eram as práticas educativas e como percebiam a função social da escola, a transposição dos conhecimentos sistematizados em práticas pedagógicas significativas e a avaliação escolar, possibilitando uma visão abrangente do que estava sendo avaliado.

Considerando-se a utilidade do roteiro de entrevista para a obtenção de informações com maior profundidade, foi usado como procedimento de coleta de dados para a Equipe Técnico-Pedagógica da Unidade Escolar, ou seja, Diretor, Diretor Adjunto, Coordenador Pedagógico. A entrevista abrangeu os seguintes aspectos: opinião sobre o cotidiano escolar, função social da escola, avaliação escolar e como eram implementadas e acompanhadas as práticas pedagógicas realizadas nos diferentes espaços da unidade escolar.

A validação dos instrumentos aconteceu no mês de março de 2010, tendo em vista a necessidade de os indicadores preliminares serem submetidos à análise dos participantes do estudo. Os questionários foram aplicados a uma amostra aleatória de $5 \%$ dos professores da escola, sorteados nos diferentes grupamentos e de $5 \%$ dos alunos, sorteados nas diferentes turmas do $5^{\circ}$ ano do EF. 0 roteiro de entrevista para Equipe Técnico-Pedagógica foi apresentado a um componente da equipe. Um especialista da área de Avaliação Educacional revisou aspectos técnicos desses instrumentos.

\section{Coleta e análise de dados}

A coleta de dados e informações ocorreu de abril a julho de 2010 . Todos os 70 alunos das turmas do $5^{\circ}$ ano do EF responderam ao questionário, na unidade escolar, durante horário de aula disponibilizado pela professora regente. Os 14 professores da unidade escolar responderam ao questionário em tempo de Centro de Estudos de modo que não houve necessidade de utilização do horário de aula. A realização da entrevista com a Equipe Técnico-Pedagógica aconteceu de maneira isolada, com cada participante, para que não houvesse influência de um na resposta do outro. 
Após a aplicação, as respostas foram apuradas e apresentadas em tabelas, contendo dados sobre as categorias, a saber: Contexto Familiar, Contexto Escolar, Atuação do Corpo Docente e Atuação do Corpo Discente.

As informações foram organizadas em categorias, com o propósito de desenvolver os procedimentos de triangulação entre as respostas dadas por professores, alunos e Especialistas, sendo comentadas em cada indicador, dentro da respectiva categoria.

Cabe ressaltar, que o processo de triangulação

envolve o exame da coerência dos resultados com diferentes fontes e métodos para mensurar o mesmo constructo [...] Quando vários métodos ou informações de diferentes fontes resultam em descobertas semelhantes, essa convergência aumenta o peso dos resultados (WORTHEN et al., 2004, p. 534).

\section{Resultados}

A análise dos dados obtidos nas categorias focalizadas nesse estudo, permite explicar os determinantes que levam a EM Santos Anjos a apresentar resultados satisfatórios no desempenho. As respostas foram dadas por 70 alunos, 14 professores e três Especialistas.

\section{Categoria contexto familiar}

Nessa categoria, observou-se o impacto do acompanhamento da família na vida escolar do educando, incluindo além da colaboração dos pais/responsáveis na execução das tarefas de dever de casa, o interesse sobre as demais atividades escolares do cotidiano do aluno.

Tabela 4 - Acompanhamento na vida escolar do aluno

\begin{tabular}{|c|c|c|c|c|}
\hline Questão & Sempre & Quase sempre & De vez em quando & Nunca \\
\hline 12.Você tem ajuda no dever de casa? & 16 & 10 & 33 & 11 \\
\hline $\begin{array}{l}\text { 14.Seus pais ou responsáveis ajudam } \\
\text { nos deveres de casa? }\end{array}$ & 17 & 13 & 30 & 10 \\
\hline $\begin{array}{l}\text { 15.Seus pais ou responsáveis cobram } \\
\text { o dever de casa? }\end{array}$ & 58 & 5 & 5 & 2 \\
\hline $\begin{array}{l}\text { 16.Você conversa sobre o que lê com } \\
\text { seus pais ou responsáveis? }\end{array}$ & 32 & 24 & 12 & 2 \\
\hline $\begin{array}{l}\text { 17.Seus pais ou responsáveis falam } \\
\text { para você tirar boas notas? }\end{array}$ & 67 & 3 & - & - \\
\hline $\begin{array}{l}\text { 18.Seus pais costumam ir às reuniões } \\
\text { e outras atividades na escola? }\end{array}$ & 56 & 8 & 6 & - \\
\hline $\begin{array}{l}\text { 19.Seus pais ou responsáveis conversam } \\
\text { sobre o que acontece na escola? }\end{array}$ & 33 & 24 & 13 & - \\
\hline
\end{tabular}

Fonte: Cardelli (2010). 
Os resultados apontados na Tabela 4 indicam que os pais e/ou responsáveis pelos alunos do $5^{\circ}$ ano do EF têm preocupação com as boas práticas de incentivo ao estudo, como forma de participação na vida escolar dos mesmos. Esse fato é observado nas respostas de frequência sempre ou quase sempre, às questões $15,16,17,18$ e 19.

Observa-se, em contraponto, que tais iniciativas se manifestam ainda tímidas no que tange à ajuda efetiva na elaboração dos trabalhos de casa (questões $12 \mathrm{e}$ 14). Uma possível explicação para o não oferecimento dessa ajuda seria o fato de os pais e/ou responsáveis não disporem de tempo para tal atividade, ou não possuírem escolaridade que permitisse tal apoio.

Com relação ao tempo gasto pelo aluno para a realização dos trabalhos de casa verificou-se que 46 dos respondentes reservam apenas uma hora do seu dia para estes deveres, o que pode ser um indicador do que foi mencionado anteriormente, quanto à pouca efetivação da ajuda dos pais e/ou responsáveis a esses alunos. Verificou-se, ainda, que apenas 8 alunos disponibilizam 3 horas ou mais para realizarem as atividades escolares em casa, reforçando seu aprendizado e demonstrando interesse nos estudos. Seria interessante ter mais alunos com maior dedicação aos estudos o que favoreceria, ainda mais, à construção de conhecimento.

\section{Categoria contexto escolar}

A ênfase dessa categoria está em informar ao leitor acerca do impacto da organização do espaço escolar no desempenho dos alunos, considerando se o espaço físico da unidade escolar tinha condições adequadas e possibilitava a articulação da práxis com a teoria pedagógica, com a metodologia utilizada pelo corpo docente e com a postura pedagógica adotada pela equipe, diante da política educacional apresentada pela SME-RJ. A Categoria Contexto Escolar incluiu quatro indicadores: organização do ambiente escolar, acesso e permanência no espaço escolar, influência do tamanho da unidade escolar no desempenho, influência do tamanho das turmas no desempenho.

\section{Indicador 1 - Organização do ambiente escolar}

Os três segmentos de participantes responderam a questões relativas a esse indicador, ou seja, alunos, professores e especialistas. 
Tabela 5 - Avaliação dos professores sobre a organização do ambiente escolar

\begin{tabular}{|c|c|c|c|c|c|}
\hline Questão & $\begin{array}{l}\text { Concordo } \\
\text { Totalmente }\end{array}$ & Concordo & Neutro & Discordo & $\begin{array}{l}\text { Discordo } \\
\text { Totalmente }\end{array}$ \\
\hline $\begin{array}{l}\text { 36. A Equipe Técnico- } \\
\text { Pedagógica dá atenção especial } \\
\text { aos aspectos relacionados com } \\
\text { as normas administrativas. }\end{array}$ & 8 & 6 & - & - & - \\
\hline $\begin{array}{l}\text { 37.A Equipe Técnico- } \\
\text { Pedagógica dá atenção especial } \\
\text { aos aspectos relacionados com } \\
\text { a manutenção da escola. }\end{array}$ & 8 & 5 & 1 & - & - \\
\hline
\end{tabular}

Fonte: Cardelli (2010).

Tabela 6 - Avaliação dos alunos sobre a organização do ambiente escolar

\begin{tabular}{l|c|c|c|c}
\hline \multicolumn{1}{c|}{ Questão } & Sempre & $\begin{array}{c}\text { Na maioria } \\
\text { das vezes }\end{array}$ & Pouco & Nada \\
\hline 2.A escola é acolhedora? & 54 & 15 & 1 & - \\
\hline $\begin{array}{l}\text { 3.0 local onde faz Educação Física é } \\
\text { adequado? }\end{array}$ & 43 & 24 & 2 & 1 \\
\hline 5.Gosta do espaço da sala de aula? & 63 & 6 & 1 & - \\
\hline
\end{tabular}

Fonte: Cardelli (2010).

Em relação ao ambiente escolar, percebe-se que as dimensões mencionadas nas Tabelas 5 e 6, obtêm a aprovação da maioria dos alunos e professores, respondentes que reconhecem a escola e a sala de aula como espaços agradáveis, além do local dedicado a atividades recreativas.

Notou-se a percepção de mais da metade dos alunos (45, de 70 ) no que se refere à existência de alguns espaços destinados à aprendizagem e às atividades extraclasse, na escola, como adequados para situações favoráveis de aprendizagem.

Conforme depoimentos obtidos na ocasião, envolvendo as questões 5, 6 e 12, o olhar dos especialistas a respeito da organização do ambiente escolar revela que a escola dá especial atenção à manutenção do prédio e aos aspectos relacionados com as normas emanadas pela SME-RJ.

A esse respeito, houve unanimidade dos Especialistas, como é exemplificado no depoimento: "(...) é imprescindivel que se tenha organização, seguindo normas estabelecidas, mas há necessidade do envolvimento de todos" (Especialista 3). 
A manutenção realizada no prédio é também sinalizada pelos três entrevistados como uma necessidade, devendo ser feita com uma certa periodicidade. A fala do Especialista reforça tal afirmação: "(..)na medida do possivel a gente faz bastante questão de ter tudo funcionando, que a escola esteja com uma aparência boa, de modo geral ela está bem conservadinha" (Especialista 3).

Ao considerar o tamanho da unidade escolar, os Especialistas concordam que a escola possui um tamanho ideal para que o fazer pedagógico apresente um resultado favorável. Na resposta do Especialista 3, "(...) procuramos cumprir as regras estabelecidas pela Secretaria de Educação, mas essa escola é do tamanho do mundo. Acolhemos todos que chegam", pode-se perceber a prática de receber bem, sem discriminação, alunos e professores.

\section{Indicador 2 - Acesso e permanência no espaço escolar}

Apenas a equipe de Especialistas da EM Santos Anjos se manifestou sobre o indicador 2, uma vez que estão diretamente relacionados com os segmentos da unidade escolar, conforme relatos às questões 1, 2, 3, 4 e 10.

Os Especialistas apontaram que a Equipe Técnico-Pedagógica anima, motiva e tem confiança no trabalho desenvolvido pela escola. É perceptivel tal afirmação nas respostas fornecidas: "[...] a Equipe Técnico-Pedagógica dá o maior incentivo a tudo que é feito aqui [...]" (Especialista 1). "A gente procura acertar. Quando fazemos algo que não dá certo, reavaliamos para melhorar" (Especialista 2).

Destaca-se o comprometimento do grupo pelos três Especialistas: "[...] todo mundo que está aqui veste a camisa. Todo mundo que está aqui fica orgulhoso com os resultados que a gente alcança [...]" (Especialista 1).

Segundo as declarações, o corpo docente possibilita situações de aprendizagem inovadoras e prazerosas. Todos estão voltados para que a escola funcione bem para atender ao aluno. Isso fica claro em: "0 grupo é bastante comprometido, porque já está junto há muito tempo. Quem chega novo se vê obrigado a seguir as regras estabelecidas" (Especialista 2). "Acho que a escola funciona bem, pois todos estão engajados e dispostos a contribuir para o bom funcionamento" (Especialista 3).

\section{Indicador 3 - Relação entre o tamanho da Unidade Escolar e o desempenho}

Esse indicador também foi respondido somente pelos Especialistas da escola, uma vez que a Equipe Técnico-Pedagógica tem acesso aos Atos Normativos 
que organizam as unidades escolares e as classificam como pequenas, médias ou grandes. Nota-se nas respostas dadas que o fato dessa escola ser de porte médio e por se tratar de uma escola da Educação Infantil ao $5^{\circ}$ ano do EF tem o seu grupo docente constituido por professores que trabalham de segundafeira a sexta-feira, cumprindo carga horária semanal de 22 horas e 30 minutos, sendo que alguns têm duas matrículas ou trabalham em regime de dupla regência, o que facilita a relação interpessoal entre os diferentes segmentos.

Percebe-se nas respostas fornecidas na entrevista com a equipe TécnicoPedagógica que os três elementos que a compõem (diretor, diretor adjunto e coordenador pedagógico) são unânimes com relação à influência do tamanho da unidade escolar no desempenho.

0 Especialista 1 informa:

"Essa escola tem o tamanho ideal [...] a gente pode conhecer cada aluno." Em "[...] a escola é do tamanho do mundo. Acolhemos todos que chegam [...]" fica visível intenção inclusiva nesse relato.

0 atendimento aos alunos da Educação Infantil ao $5^{\circ}$ ano do EF facilita 0 entrosamento entre os professores, a equipe gestora e os demais segmentos da unidade escolar, o que influencia diretamente o desempenho do corpo discente.

\section{Indicador 4 - Relação entre o tamanho das turmas e o desempenho}

Os Especialistas concordaram com relação ao quantitativo de alunos em sala de aula, favorecendo o desempenho satisfatório dos alunos dos grupamentos da Educação Infantil ao $5^{\circ}$ ano do EF, uma vez que estão formados de acordo com a Portaria E/SUBE/CED de 05/11/2009. Fica evidenciado nas assertivas dos Especialistas que:

\footnotetext{
"As turmas tem um quantitativo adequado o que permite diversificação das práticas e o bom desempenho dos alunos" (Especialista 2).

"Os alunos são agrupados de acordo com determinação da SME. Com um número adequado de alunos temos a garantia de bom desempenho" (Especialista 3).
}

\section{Categoria atuação do corpo docente}

A Categoria Atuação do Corpo Docente é composta por nove indicadores, compreendendo o perfil constitui o corpo docente da EM Santos Anjos (gênero, faixa etária, escolaridade), e perguntas sobre as formas com que 
as práxis pedagógicas desses professores e a avaliação do processo escolar influenciam nos resultados apresentados pelos alunos. Além disso, procurouse em verificar se o fazer pedagógico considera os saberes trazidos pelos alunos, com propostas de atividades que levem os educando a se tornarem autônomos, com utilização de materiais didáticos adequados, levando, dessa maneira, à aprendizagem significativa.

\section{Indicador 1 - Gênero}

No que diz respeito ao gênero do corpo docente da escola, há a prevalência do sexo feminino, pois todos os 14 docentes são mulheres, demonstrando que, apesar das mudanças contemporâneas, ser professor ainda se configura uma responsabilidade feminina.

\section{Indicador 2 - Faixa etária}

Em relação à idade, observa-se que a faixa etária predominante é constituída de professores acima de 45 anos, podendo-se inferir que existem indicadores de maturidade e compromisso no desenvolvimento da atividade docente.

\section{Indicador 3 - Experiência profissional}

Nesse indicador foi considerada a qualificação profissional do corpo docente e se havia preparação para enfrentar os desafios encontrados no trabalho com essa clientela. $E$, ainda, se a formação profissional, aliada à experiência profissional e à faixa etária, contribui para que a escola se torne um espaço com nível de excelência.

0 corpo docente da EM Santos Anjos apresenta um alto padrão de qualificação, o que parece refletir a preocupação do profissional em investir na sua formação continuada com a finalidade de aprimorar suas práticas pedagógicas. Do total de 14 , 12 professores possuem formação universitária. Em contraponto, esse investimento em qualificação pode significar também, que o profissional almeja uma ascensão funcional no mercado de trabalho.

Já no que tange ao número de anos no magistério, pode-se perceber a permanência da metade dos professores dessa escola, por mais de 20 anos de efetivo exercício na carreira, e de três, por mais de 10 anos. Possivelmente esses profissionais exercem suas funções não só por necessidade, mas pela satisfação no desempenho da atividade docente.

\section{Indicador 4 - Qualidade do planejamento do professor}

As respostas ao quarto indicador da categoria atuação do corpo docente estão resumidas na Tabela 7. 
Tabela 7 - Uso de material de apoio pedagógico

\begin{tabular}{|c|c|c|c|c|}
\hline Questão & $\begin{array}{l}\text { Sim, } \\
\text { utilizo }\end{array}$ & $\begin{array}{c}\text { Não utilizo } \\
\text { porque } \\
\text { não acho } \\
\text { necessário }\end{array}$ & $\begin{array}{l}\text { Não utilizo } \\
\text { porque a escola } \\
\text { não tem }\end{array}$ & Não \\
\hline 5. Você utiliza computador? & 11 & 1 & - & 2 \\
\hline 6. Você utiliza Internet? & 9 & 1 & - & 4 \\
\hline 7. Você utiliza Fitas de vídeo ou DVD? & 14 & - & - & - \\
\hline $\begin{array}{l}\text { 8. Você utiliza jornais e revistas } \\
\text { informativas? }\end{array}$ & 14 & - & - & - \\
\hline $\begin{array}{l}\text { 9. Você utiliza livros de consulta para } \\
\text { professores? }\end{array}$ & 13 & - & - & 1 \\
\hline $\begin{array}{l}\text { 10. Você utiliza livros de leitura } \\
\text { (literatura infantil)? }\end{array}$ & 14 & - & - & - \\
\hline 11. Você utiliza livros didáticos? & 13 & 1 & - & - \\
\hline 12. Você utiliza data show? & - & 2 & 9 & 3 \\
\hline 13.Você utiliza máquina copiadora? & 13 & - & 1 & - \\
\hline 14. Você utiliza filmadora? & 2 & 5 & 3 & 4 \\
\hline
\end{tabular}

Fonte: Cardelli (2010).

Ainda nas questões dos professores, percebe-se a adesão aos recursos de mídias, como valor agregado às práticas pedagógicas convencionais, integrantes da agenda do conjunto dos profissionais docentes dessa escola. Nota-se a utilização de materiais pedagógicos que contribuem para que as práticas pedagógicas sejam progressistas e motivadoras, auxiliando no processo de construção de conhecimento dos alunos, tornando os espaços existentes na unidade escolar favoráveis à aprendizagem (Tabela 7).

Tabela 8 - Práxis pedagógica dos professores

\begin{tabular}{c|c|c|c|c|c}
\hline \multicolumn{1}{c|}{ Questão } & Nunca & $\begin{array}{c}\text { Poucas } \\
\text { vezes }\end{array}$ & Às vezes & $\begin{array}{c}\text { Muitas } \\
\text { vezes }\end{array}$ & $\begin{array}{c}\text { Todas as } \\
\text { vezes }\end{array}$ \\
\hline $\begin{array}{l}\text { 15. Você utiliza os conhecimentos } \\
\text { adquiridos em atividades de formação } \\
\text { continuada para a melhoria de sua } \\
\text { prática pedagógica? }\end{array}$ & - & - & 2 & 9 & 3 \\
\hline
\end{tabular}


(Continuação)

\begin{tabular}{l|c|c|c|c|c}
\hline $\begin{array}{l}\text { 16. Planeja as atividades pedagógicas } \\
\text { na ótica dos excluídos sociais? }\end{array}$ & 3 & - & 2 & 3 & 6 \\
\hline $\begin{array}{l}\text { 17. Implementa ações pedagógicas } \\
\text { baseadas em práxis dialógica? }\end{array}$ & - & - & - & 6 & 8 \\
\hline $\begin{array}{l}\text { 19. Possibilita a troca de experiências } \\
\text { entre os alunos? }\end{array}$ & - & - & - & 4 & 10 \\
\hline $\begin{array}{l}\text { 20. Utiliza o acervo da Sala de Leitura } \\
\text { nas práticas pedagógicas? }\end{array}$ & - & - & 2 & 8 & 4 \\
\hline $\begin{array}{l}\text { 21. Faz uso de diferentes materiais } \\
\text { pedagógicos em suas práticas? }\end{array}$ & - & - & - & 7 & 7 \\
\hline
\end{tabular}

Fonte: Cardelli (2010).

Analisando as respostas ao grupo de questões constantes da Tabela 8, verificase uma tendência positiva dos professores, na utilização de conhecimentos adquiridos em educação permanente, nas práticas pedagógicas, bem como o seu planejamento, levando os educandos à participação efetiva, promovendo diálogo, troca de experiências em função da diversidade pedagógica utilizada nos diferentes contextos de aprendizagem. No entanto, há que se considerar que, com relação ao planejamento de atividades pedagógicas na ótica dos excluídos sociais (questão 16), ainda se percebe um modesto olhar com relação à necessidade.

$\mathrm{Na}$ perspectiva dos Especialistas, o grupo de professores e a Equipe TécnicoPedagógica são bastante entrosados, o que facilita a realização de práticas pedagógicas que levam os alunos à construção de conhecimento.

Com relação aos Especialistas da EM Santos Anjos, para os resultados referentes ao indicador adequação do planejamento do professor, foram consideradas as questões 7,8 e 9 da entrevista. 0 diálogo está presente nas relações interpessoais, o que estabelece uma relação de respeito e valorização do trabalho do outro. Os espaços de Centros de estudos são utilizados para troca de ideias entre os professores. Na fala dos Especialistas: "Levam em consideração as intervenções da Equipe Técnico-Pedagógica, pois a Coordenadora Pedagógica é muito amiga, sabe cobrar na hora certa e o grupo tem confiança nela" (Especialista 1). "0 trabalho é coletivo. Todos se envolvem. A troca de experiência é constante" (Especialista 3). "Os professores dialogam com seus pares e também trocam com os outros dos demais anos de escolaridade, distribuindo aquilo que será ensinado, sem desconsiderar as determinações da SME-RJ" (Especialista 2). 


\section{Indicador 5 - Adequação dos conteúdos aos objetivos de ensino}

Nesse indicador foram coletados posicionamentos de professores e especialistas da equipe da unidade escolar.

Observou-se, quase que unanimemente, 12 dos 14 respondentes sinalizaram que muitas vezes, ou todas as vezes, os objetivos propostos estão adequados aos conteúdos de ensino. Os objetivos constam do planejamento dos professores e este está em consonância com o Projeto Político Pedagógico da unidade escolar, logo se pode inferir que é o eixo norteador do trabalho pedagógico.

\section{Indicador 6 - Ação educativa comprometida com a construção de uma sociedade justa e solidária}

Nesse indicador foram analisadas algumas questões já apresentadas, que reforçam o comprometimento da equipe com o objetivo de construção de uma sociedade justa e solidária, que dê oportunidades a todos os cidadãos

Tabela 9 - Ação educativa e construção de sociedade justa e solidária, segundo os professores

\begin{tabular}{l|c|c|c|c|c}
\hline \multicolumn{1}{c|}{ Questão } & Nunca & $\begin{array}{c}\text { Poucas } \\
\text { vezes }\end{array}$ & $\begin{array}{c}\text { Ás } \\
\text { vezes }\end{array}$ & $\begin{array}{c}\text { Muitas } \\
\text { vezes }\end{array}$ & $\begin{array}{c}\text { Todas } \\
\text { as } \\
\text { vezes }\end{array}$ \\
\hline $\begin{array}{l}\text { 16. Planeja as atividades pedagógicas } \\
\text { na ótica dos excluidos sociais? }\end{array}$ & 3 & - & 2 & 3 & 6 \\
\hline $\begin{array}{l}\text { 17. Implementa ações pedagógicas } \\
\text { baseadas em práxis dialógica? }\end{array}$ & - & - & - & 6 & 8 \\
\hline $\begin{array}{l}\text { 23. As atividades propostas em } \\
\text { sala de aula possibilitam a troca de } \\
\text { experiências entre os alunos? }\end{array}$ & - & - & 1 & 6 & 7 \\
\hline $\begin{array}{l}\text { 24. As atividades realizadas em sala } \\
\text { de aula têm relação com o Projeto } \\
\text { Político Pedagógico? }\end{array}$ & - & - & - & 3 & 11 \\
\hline
\end{tabular}

Fonte: Cardelli (2010).

Percebe-se que o resultado demonstrado na Tabela 9, na ótica do corpo docente, aponta positivamente para as questões postuladas sobre ação educativa e construção de uma sociedade mais justa e solidária, uma vez que refletem uma interação adequada entre as atividades pedagógicas programadas e os objetivos do ensino propostos, não somente na realidade da comunidade, como também nos fatores 
associados à troca de experiências, prática dialógica nas situações de aprendizagem, relação lógica entre "o quê", "o como" e "o porquê" será ensinado.

O Projeto Político Pedagógicos estabelece uma relação direta com o que está sendo realizado em sala de aula. Ainda assim, pode-se considerar que existe certa incipiência com relação ao planejamento de atividades pedagógicas, na ótica dos excluídos sociais.

\section{Indicador 7 - Prática Pedagógica}

$\mathrm{Na}$ composição das respostas às questões relacionadas ao Indicador 7, sobre a prática pedagógica dos professores, observa-se a opinião do corpo docente sobre a atuação da Equipe Técnico-Pedagógica e ainda a atitude desta em relação entre os professores e os demais membros da equipe da unidade escolar (questões 31 a 45).

Tabela 10 - Prática Pedagógica dos professores

\begin{tabular}{l|c|c|c|c|c}
\hline \multicolumn{1}{c|}{ Questão } & $\begin{array}{c}\text { Concordo } \\
\text { Total- } \\
\text { mente }\end{array}$ & $\begin{array}{c}\text { Concor- } \\
\text { do }\end{array}$ & Neutro & $\begin{array}{c}\text { Disc- } \\
\text { ordo }\end{array}$ & $\begin{array}{c}\text { Discordo } \\
\text { Total- } \\
\text { mente }\end{array}$ \\
\hline $\begin{array}{l}\text { 31. A Equipe Técnico-Pedagógica me } \\
\text { anima e me motiva para o trabalho. }\end{array}$ & 10 & 3 & 1 & - & - \\
\hline $\begin{array}{l}\text { 32. Tenho plena confiança na Equipe } \\
\text { Técnico-Pedagógica como profissional. }\end{array}$ & 9 & 5 & - & - & - \\
\hline $\begin{array}{l}\text { 33. A Equipe Técnico-Pedagógica } \\
\text { consegue que os professores se } \\
\text { comprometam com a escola. }\end{array}$ & 8 & 6 & - & - & - \\
\hline $\begin{array}{l}\text { 34. A Equipe Técnico-Pedagógica } \\
\text { estimula as atividades inovadoras. }\end{array}$ & 8 & 5 & 1 & - & - \\
\hline $\begin{array}{l}\text { 35. A Equipe Técnico-Pedagógica } \\
\text { dá atenção especial a aspectos } \\
\text { relacionados com a aprendizagem } \\
\text { dos alunos. }\end{array}$ & 10 & 4 & - & - & - \\
\hline $\begin{array}{l}\text { 38. Sinto-me respeitado(a) pela Equipe } \\
\text { Técnico-Pedagógica. }\end{array}$ & 9 & 5 & - & - & - \\
\hline $\begin{array}{l}\text { 39. Respeito a Equipe Técnico- } \\
\text { Pedagógica. }\end{array}$ & 11 & 3 & - & - & - \\
\hline $\begin{array}{l}\text { 40. Participo das decisões relacionadas } \\
\text { com o meu trabalho. }\end{array}$ & 8 & 6 & - & - & - \\
\hline $\begin{array}{l}\text { 41. A equipe de professores leva em } \\
\text { consideração minhas ideias. }\end{array}$ & 5 & 6 & 3 & - & - \\
\hline
\end{tabular}


(Continuação)

\begin{tabular}{l|c|c|c|c|c}
\hline $\begin{array}{l}\text { 42. Eu levo em consideração as ideias } \\
\text { de outros colegas. }\end{array}$ & 6 & 6 & 2 & - & - \\
\hline $\begin{array}{l}\text { 43. 0 ensino que a escola oferece aos } \\
\text { alunos é muito influenciado pela troca } \\
\text { de ideias entre os professores. }\end{array}$ & 8 & 4 & 2 & - & - \\
\hline $\begin{array}{l}\text { 44. Os professores desta escola } \\
\text { procuram coordenar o conteúdo das } \\
\text { disciplinas entre os diferentes anos de }\end{array}$ & 8 & 6 & - & - & - \\
escolaridade. & 11 & 3 & - & - & - \\
\hline $\begin{array}{l}45.0 \text { diretor, professores e demais } \\
\text { membros da equipe da escola colaboram } \\
\text { para fazer esta escola funcionar bem. }\end{array}$ & 11 & & & & \\
\hline
\end{tabular}

Fonte: Cardelli (2010).

A Tabela 10 trata da base de estruturação pedagógica e administrativa da escola, retratada pelos professores com um padrão de aprovação bastante satisfatório, 0 que de certa forma, tem ressonância no desempenho dos alunos.

De acordo como o olhar do corpo docente, observa-se um indicador positivo de participação e entrosamento entre a equipe técnico pedagógica, os professores e demais membros das equipes da escola, corroborando o resultado já analisado na Tabela 9. No entanto, percebe-se uma postura de neutralidade com relação à troca e aceitação de ideias entre alguns professores e as possiveis influências nas situações de aprendizagem oferecidas aos alunos (questões 41, 42 e 43). Esse não posicionamento corresponde a discordância ou ainda a falta de entrosamento com os colegas.

Os Especialistas, com relação ao indicador Prática Pedagógica, relataram que existe comprometimento com o trabalho desenvolvido, o que favorece o envolvimento do grupo e a participação de todos. Percebe-se isso nos depoimentos dados:

"[...] a Coordenadora Pedagógica é muito amiga, sabe cobrar na hora certa e o grupo tem confiança nela" (Especialista 1). "O diálogo faz parte na prática dessa escola. Todos podem manifestar sua opinião" (Especialista 3).

\section{Indicador 8 - Qualidade dos materiais pedagógicos utilizados pelos docentes}

0 resultado obtido reafirma o compromisso dos professores com a qualidade do ensino realizado na escola, pois dos respondentes, 13 utilizam o livro didático. Percebe- 
se que, conforme orientações do MEC, o corpo docente analisa, escolhe e utiliza os livros didáticos recomendados pelo Programa Nacional do Livro Didático (PNLD).

Observando os dados contidos na Tabela 8, ratifica-se a diversidade de diferentes materiais de apoio pedagógico e a grande adesão aos recursos de mídias. Esses recursos representam ferramentas indispensáveis no mundo atual (globalizado) e, principalmente, pela apropriação de tantas outras pelos próprios alunos. Porém, verificam-se ainda algumas resistências aos usos dessas tecnologias (questões 5, 6, 12 e 14, na Tabela 7). As práticas pedagógicas ditas convencionais fazem parte do dia a dia, por muitos anos, percebendo-se que a adesão é total. Já as novas tecnologias, ainda enfrentam alguns problemas de assimilação, em função do desconhecimento ou resistência com relação à apropriação desses novos saberes.

\section{Indicador 9 - Avaliação do ensinoaprendizagem}

Tabela 11 - Avaliação do processo escolar, segundo os professores

\begin{tabular}{l|c|c|c|c|c}
\multicolumn{1}{c|}{ Questão } & $\begin{array}{c}\text { Nun- } \\
\text { ca }\end{array}$ & $\begin{array}{c}\text { Poucas } \\
\text { vezes }\end{array}$ & $\begin{array}{c}\text { Às } \\
\text { vezes }\end{array}$ & $\begin{array}{c}\text { Muitas } \\
\text { vezes }\end{array}$ & $\begin{array}{c}\text { Todas } \\
\text { as } \\
\text { vezes }\end{array}$ \\
\hline $\begin{array}{l}\text { 26.Você tem o hábito de analisar os resultados } \\
\text { das avaliações de Rede? }\end{array}$ & - & 1 & - & 4 & 9 \\
\hline $\begin{array}{l}\text { 27.Você conhece os resultados do Sistema } \\
\text { Nacional de Avaliação da Educação Básica } \\
\text { (SAEB)? }\end{array}$ & 1 & 1 & - & 5 & 7 \\
\hline $\begin{array}{l}\text { 28. Avalia seus alunos a partir do que foi } \\
\text { definido no Planejamento Educacional e PPP? }\end{array}$ & - & 1 & - & 2 & 11 \\
\hline $\begin{array}{l}\text { 29. Sua escola participou da Prova Brasil } \\
\text { em 2009? }\end{array}$ & - & - & - & - & 14 \\
\hline $\begin{array}{l}\text { 30. Você tem conhecimento do IDEB de sua } \\
\text { escola? }\end{array}$ & - & - & - & - & 14 \\
\hline
\end{tabular}

Fonte: Cardelli (2010).

Segundo os dados constantes na Tabela 11, percebe-se um indicador positivo de engajamento dos professores nas políticas de avaliação educacional, embora dois dos respondentes tenham informado que nunca ou pouco conheciam o SAEB. Considerando, ainda, os professores respondentes, aponta-se para um reconhecimento da avaliação no processo de aprendizagem realizado EM Santos Anjos, uma vez que são implementadas ações pedagógicas embasadas em suas recomendações. Nota-se que todos têm conhecimento do IDEB e da participação dos alunos na Prova Brasil e, que tais resultados influenciam na tomada de decisões da equipe da escola. 


\section{Categoria atuação do corpo discente}

Essa categoria trata das questões relacionadas com os principais envolvidos no processo pedagógico. Sendo assim, procurou-se definir o perfil de aluno do $5^{\circ}$ ano do EF da EM Santos Anjos considerando o gênero, as experiências trazidas pelos alunos, as situações de aprendizagem propostas, a relação professor/aluno e 0 envolvimento no coletivo escolar.

\section{Indicador 1 - Gênero}

A maioria dos alunos do $5^{\circ}$ ano do EF EM Santos Anjos é do sexo masculino (41 respondentes) e 29 do sexo feminino.

\section{Indicador 2 - Experiências trazidas pelos alunos}

Tabela 12 - Integração com situações de construção de conhecimento

\begin{tabular}{l|c|c|c|c}
\hline Questão & Sempre & $\begin{array}{c}\text { Muitas } \\
\text { vezes }\end{array}$ & $\begin{array}{c}\text { Poucas } \\
\text { vezes }\end{array}$ & Nunca \\
\hline $\begin{array}{l}\text { 25. Você costuma participar das aulas? } \\
\text { 26. Quando você quer falar, seus } \\
\text { professores costumam dar atenção? }\end{array}$ & 54 & 12 & 3 & 1 \\
\hline
\end{tabular}

Fonte: Cardelli (2010).

$\mathrm{Na}$ Tabela 12, reafirmam-se os indicadores apontados nas informações dos especialistas e dos professores com relação à participação e interação dos mesmos com os alunos, no desenvolvimento das atividades pedagógicas que levem à aprendizagem significativa. Todavia, nota-se que 4 respondentes informaram que poucas vezes ou nunca os professores mantêm uma prática dialógica na sala de aula. Isso possivelmente pode acontecer, devido à diferença no estilo de ensinar dos professores.

\section{Indicador 3 - Qualidade das situações de aprendizagem}

Existe uma tendência de avaliação positiva com relação ao ambiente de atividades de Educação Física presentes no relato dos professores e especialistas. Pode-se afirmar que 69 , dos 70, respondentes consideram o espaço destinado às atividades recreativas como sendo muitas vezes ou sempre adequado para realização dessas práticas. 
Segundo 45 dos alunos respondentes, existem alguns espaços interessantes para práticas pedagógicas, mas 10 dos respondentes disseram que há poucos espaços, o que aponta para possível necessidade de diversificação dos espaços destinados à realização das atividades.

Tabela 13 - Situações de aprendizagem, segundo os alunos

\begin{tabular}{|c|c|c|c|c|}
\hline Questão & Sempre & $\begin{array}{l}\text { Quase } \\
\text { sempre }\end{array}$ & $\begin{array}{c}\text { De vez } \\
\text { em quando }\end{array}$ & Nunca \\
\hline $\begin{array}{l}\text { 7. Você costuma frequentar a sala de } \\
\text { leitura? }\end{array}$ & 53 & 10 & 7 & - \\
\hline 8. Você lê histórias em quadrinhos? & 15 & 30 & 24 & 1 \\
\hline 9. Você costuma ler livros infantis? & 12 & 18 & 32 & 8 \\
\hline $\begin{array}{l}\text { 10. Você tem hábito de ler ou fazer } \\
\text { empréstimos de livros na Sala de Leitura? }\end{array}$ & 49 & 10 & 9 & 2 \\
\hline $\begin{array}{l}\text { 11. Você tem hábito de fazer trabalhos } \\
\text { utilizando jornais em sala de aula? }\end{array}$ & 6 & 14 & 47 & 3 \\
\hline 25. Você costuma participar das aulas? & 63 & 7 & - & - \\
\hline $\begin{array}{l}\text { 36. Você pode pedir ajuda aos colegas } \\
\text { quando apresenta dificuldades? }\end{array}$ & 18 & 23 & 23 & 6 \\
\hline $\begin{array}{l}\text { 37. Você costuma trabalhar em grupo } \\
\text { com seus colegas nas atividades de sala } \\
\text { de aula? }\end{array}$ & 11 & 16 & 42 & 1 \\
\hline $\begin{array}{l}\text { 38. Você costuma ajudar a seus colegas } \\
\text { a progredirem? }\end{array}$ & 20 & 29 & 19 & 2 \\
\hline $\begin{array}{l}\text { 39. Você presta atenção quando os } \\
\text { professores estão explicando? }\end{array}$ & 51 & 18 & 1 & - \\
\hline
\end{tabular}

Fonte: Cardelli (2010).

Percebe-se na Tabela 13, uma resposta positiva relativa às situações de aprendizagem desenvolvidas nos diferentes espaços de construção de conhecimento, o que também está presente nas respostas dos professores e especialistas. Por outro lado, a cooperação e integração entre os alunos parece pouco estimulada nas práticas de sala de aula (questões 36 e 37). Há necessidade do uso de diferentes materiais pedagógicos que estimulem o trabalho com diferentes gêneros textuais o que ampliaria mais as habilidades de leitura e escrita dos alunos (questões 8, 9 
e 11). Cabe ressaltar, ainda, que as situações de aprendizagem (questões 8, 9 e 11) revelam a carência de leitura, típica da cultura escolar brasileira.

\section{Indicador 4 - Relação professor/aluno}

Contatou-se um grau de satisfação dos alunos com seus professores bastante positivo, reforçando a real necessidade de que se as relações no espaço escolar estiverem bem estruturadas, as chances de sucesso serão maiores. Cabe ao professor fazer a mediação desse processo, tornando a relação professor/aluno uma verdadeira parceria.

Tabela 14 - Relacionamento dos envolvidos no processo de ensino e aprendizagem

\begin{tabular}{|c|c|c|c|c|}
\hline Questão & Sempre & $\begin{array}{c}\text { Muitas } \\
\text { vezes }\end{array}$ & $\begin{array}{r}\text { Poucas } \\
\text { vezes } \\
\end{array}$ & Nunca \\
\hline 21. Seus professores explicam bem? & 59 & 9 & 2 & - \\
\hline $\begin{array}{l}\text { 22. Seus professores explicam de uma maneira } \\
\text { que você não entende? }\end{array}$ & 3 & 4 & 41 & 22 \\
\hline $\begin{array}{l}\text { 23. Seus professores ensinam de maneira } \\
\text { divertida? }\end{array}$ & 29 & 22 & 18 & 1 \\
\hline $\begin{array}{l}\text { 24. Seus professores dão importância ao que } \\
\text { você fala? }\end{array}$ & 44 & 23 & 2 & 1 \\
\hline 25. Você costuma participar das aulas? & 63 & 7 & - & - \\
\hline $\begin{array}{l}\text { 26. Quando você quer falar, seus professores } \\
\text { costumam dar atenção? }\end{array}$ & 54 & 12 & 3 & 1 \\
\hline $\begin{array}{l}\text { 27. Seus professores têm o hábito de dizer no } \\
\text { início da aula o que vão fazer? }\end{array}$ & 34 & 17 & 16 & 3 \\
\hline $\begin{array}{l}\text { 28. Quando você não compreende o que é } \\
\text { explicado, seus professores repetem? }\end{array}$ & 50 & 15 & 5 & - \\
\hline $\begin{array}{l}\text { 29. Seus professores explicam de várias maneiras } \\
\text { a mesma coisa? }\end{array}$ & 32 & 24 & 12 & 2 \\
\hline $\begin{array}{l}\text { 30. Quando você pede explicação, seus } \\
\text { professores ajudam? }\end{array}$ & 53 & 12 & 5 & - \\
\hline $\begin{array}{l}\text { 31. Seus professores comentam os erros quando } \\
\text { devolvem os trabalhos, testes e provas? }\end{array}$ & 39 & 20 & 8 & 3 \\
\hline
\end{tabular}

Fonte: Cardelli (2010).

Verifica-se na Tabela 14 revelam que existe comunicação efetiva entre os professores e seus alunos. É bastante representativo o fato de os professores explicarem o mesmo conteúdo de várias formas diferentes (questão 29). Destacase, também, o fato de nem sempre o aluno entender o que lhe é explicado logo no início, e o professor ter a sensibilidade de, em algumas situações de ensino e aprendizagem, repetir a explicação (questão 28). Dessa maneira, os professores devem conseguir o melhor dos alunos, levando em consideração as limitações de cada um. Observa-se, ainda, o fato da importância dada ao fato do professor levar 
em conta o que é destacado pelo aluno, tornando o aprendizado numa via de dupla fluência (questão 24).

Nota-se que 18 dos respondentes consideram que poucas vezes (questão 23) seus professores ensinam de maneira divertida, mas isso não impede que os alunos reconheçam que explicam bem (questões 21 e 22). Ainda se observa que 16 dos respondentes sinalizam que poucas vezes seus professores informam no início da aula o que vão fazer (questão 27), o que reflete uma tendência da pedagogia liberal tradicional.

\section{Indicador 5 - Envolvimento no coletivo escolar.}

Identificou-se pelas respostas dos alunos, que 48 dos respondentes apreciam a merenda escolar. Cabe observar, no entanto, se tal afirmativa está relacionada ao padrão socioeconômico dos mesmos. A escola mantém o nível da merenda, com regras rígidas de higiene e escolha correta do cardápio, conforme orientações do Instituto de Nutrição do município do Rio de Janeiro.

Tabela15 - Envolvimento no coletivo escolar

\begin{tabular}{|c|c|c|c|c|}
\hline Questão & Sempre & $\begin{array}{c}\text { Muitas } \\
\text { vezes }\end{array}$ & $\begin{array}{c}\text { Poucas } \\
\text { vezes }\end{array}$ & Nunca \\
\hline 32. Você aprende muito na escola? & 60 & 10 & - & - \\
\hline 33. Nas aulas, consegue-se trabalhar bem? & 48 & 18 & 4 & - \\
\hline $\begin{array}{l}\text { 34. Quando o professor sai da sala, você continua } \\
\text { trabalhando? }\end{array}$ & 28 & 23 & 18 & 1 \\
\hline 35. Nas aulas, você respeita sua vez de falar? & 49 & 17 & 4 & - \\
\hline $\begin{array}{l}\text { 37. Você costuma trabalhar em grupo com seus } \\
\text { colegas nas atividades de sala de aula? }\end{array}$ & 11 & 16 & 42 & 1 \\
\hline
\end{tabular}

Fonte: Cardelli (2010).

Na Tabela 15, observa-se uma convergência, nas respostas dos alunos, uma vez que aponta para a participação, interação, entrosamento e compromisso dos professores com o processo de aprendizagem realizado nessa escola, reafirmando positivamente o contido nas respostas dos professores e especialistas.

0 nível de aprendizado reconhecido pelos próprios alunos é altamente satisfatório, ou seja, eles reconhecidamente aprendem em sala de aula. Pode-se ainda explorar os trabalhos em grupos em sala de aula. Essas atividades precisam ser bem coordenadas para que mantenham certo grau de organização. Talvez o maior 
problema esteja no fato de nem sempre se conseguir manter certa organização e concentração necessária para os trabalhos em grupo (questão 37).

\section{Considerações e recomendações}

As considerações finais com relação aos fatores que levaram a EM Santos Anjos a apresentar sucesso em suas práticas, mesmo sendo uma unidade inserida em contexto de risco.

\section{Considerações}

Como foi visto até agora, uma escola de qualidade é caracterizada por vários fatores que podem ser evidenciados além dos resultados apresentados, a partir de informações coletadas e analisadas, considerando os diferentes segmentos da unidade escolar, ou seja, os pais/responsáveis, os alunos, os professores, a equipe gestora e demais membros da comunidade escolar.

Essas informações, por outro lado, podem ser separadas em dois grandes grupos. Um se refere à unidade escolar, com os professores, a equipe gestora, a proposta pedagógica implementada, a conservação da rede física, as políticas públicas implementadas, a relação estabelecida entre os sujeitos do processo, o que exerce uma influência direta no fazer pedagógico da instituição. 0 outro grupo está diretamente relacionado ao cotidiano do aluno, a participação de suas famílias no trabalho pedagógico realizado pela escola e o contexto socioeconômico em que se encontram esses indivíduos.

A respeito de trabalho pedagógico, Libâneo (1985, p. 133-134) aponta que

0 trabalho formativo, portanto, supõe elementos pedagógico-didáticos como fatores, específicos do ensino, sempre socialmente contextualizados; supõe o professor atuando como mediador entre o aluno e as matérias,entre um sujeito motivado e interessado no saber e os conteúdos culturais vivos, problematizados no confronto com a realidade social.

Os resultados da avaliação refletem que o bom desempenho dessa unidade escolar está diretamente ligado à autonomia desempenhada pelo grupo, à utilização de práticas pedagógicas que favorecem à aprendizagem dos alunos.

A gestão participativa foi outro fator relevante para o bom resultado apresentado pela escola, uma vez que sua função de mediadora, em todas as situações ocorridas no espaço escolar, foi feita de forma dialógica, procurando a articulação, a participação e a opinião dos diferentes segmentos que constituem o grupo. Existe grande empenho e comprometimento da equipe gestora com o trabalho desempenhado pelos 
diferentes segmentos da unidade escolar, organizando atividades e eventos variados, implementando, assim, o Projeto Político Pedagógico, integrando e estimulando toda a comunidade escolar, na atuação como cidadãos compromissados e participantes.

Cada escola é única, tem características particulares, um perfil específico, uma clientela com sua própria história, mas alguns fatores são determinantes para o sucesso escolar. É possivel destacar que o sucesso dos alunos da EM Santos Anjos está associado, de maneira geral, aos seguintes fatores: participação da família e da comunidade, embora de forma tímida; confiança do professor na capacidade dos alunos, levando a altas expectativas com relação à aprendizagem; participação ativa da equipe gestora o que marca a necessidade de uma liderança ativa na escola; comprometimento da escola, como um todo, considerando que independente da metodologia utilizada, o mais importante é dar sentido ao que está sendo ensinado; atenção dada às atividades realizadas no espaço escolar; realização de trabalho de casa; rede física conservada e acolhedora; proposta pedagógica definida com práticas contextualizadas e significativas; atividades diversificadas para atendimento às diferenças individuais dos alunos; adequação dos objetivos e planejamentos à realidade local; utilização de material de apoio pedagógico adequado; nivel de escolaridade do corpo docente elevado (superior completo); realização de dever de casa e reforço escolar; e ainda as relações interpessoais favoráveis na sala de aula e na escola.

A prática pedagógica desenvolvida na EM Santos Anjos parece que vem contribuindo para minimizar as dificuldades presentes no cotidiano escolar. Por um lado, a equipe da escola está ciente de que existe uma real necessidade de maior participação da família no trabalho da escola. A equipe não se curvou diante das dificuldades socioeconômicas apresentadas nesse tipo de contexto e vem trabalhando, sem receitas prontas ou fórmulas mágicas, mas com compromisso e seriedade que 0 ato de ensinar exige. Foi com compromisso, simplicidade, amor, dedicação, prática dialógica que essa equipe de professores, essa equipe gestora, esses pais/responsáveis e esses alunos podem ser considerados vencedores, pois eles fizeram a diferença. Isso prova que educação de qualidade em uma escola inserida em área risco é possivel sim.

\section{Recomendações}

Tendo em vista os resultados do estudo, houve a preocupação com fatores que, possivelmente, explicam sucesso da EM Santos Anjos, inserida em área de risco, o que se possibilita recomendar que:

a) EM Santos Anjos continue implementando práticas pedagógicas inovadoras, prazerosas, que atendam de maneira eficiente e eficaz a clientela da Cruzada São Sebastião e arredores; busque mais investimento na utilização de mídias variadas e, principalmente, novas tecnologias educacionais; solicite e incentive um maior envolvimento da família, no acompanhamento das ati- 
vidades extraescolares; incentive os alunos a dedicarem maior tempo para a realização das tarefas diárias; procure fazer com que os professores interajam mais com a turma em suas aulas, tornando-as participativas e com atividades pedagógicas sempre contextualizadas;

b) a SME/RJ procure valorizar práticas pedagógicas contextualizadas e de sucesso, incentivando e investindo em políticas públicas que favoreçam outras unidades escolares inseridas em comunidades de contexto similar; invista na formação das equipes docentes, bem como, das equipes gestoras;

c) outras escolas conheçam que é importante o envolvimento de todo o corpo docente, mediante uma proposta pedagógica clara, a qual leve os alunos à efetiva construção de conhecimento, que promova a unidade escolar como efetivo espaço de aprendizagem, e que sirva de mediação da equipe gestora nas ações administrativas, pedagógicas e culturais desenvolvidas pela escola.

\section{Referências}

BECKER, F. da R. Avaliação educacional em larga escala: a experiência brasileira. Revista Ibero-americana de Educação, [S.I.], n. 53/1, 25 jun. 2010.

BRASIL. Lei $n^{\circ}$. 9.394, de 20 de dezembro de 1996. Estabelece as diretrizes e bases da educação nacional. Diário Oficial [da] República Federativa do Brasil, Brasília, DF, 23 dez. 1996.

BROOKOVER, W. B. et al. School social systems and students achievement:schools can make a difference. New York: Praeger, 1979.

CARDELLI, D. T. Avaliação por diferentes olhares: fatores que explicam o sucesso de escola carioca em área de risco. 2010. 66f. Dissertação (Mestrado Profissional em Avaliação) - Programa de Pós-Graduação em Avaliação, Fundação Cesgranrio, Rio de Janeiro, 2010.

HILL, P. W.; ROWE, K. J.; JONES, T. SIIS: school improvement information service. Version 1.1. Melbourne: University of Melbourne, Centre for Applied Educational Research, 1995.

HOFFMANN, J. Avaliar: respeitar primeiro, educar depois. Porto Alegre: Mediação, 2003.

INEP. Resultados: todos podem consultar os resultados da Prova Brasil e Saeb. Brasilia, DF, 2009. Disponivel em: <http://provabrasil.inep.gov.br/resultados>. Acesso em: 20 set. 2009. 
LIBÂNEO, J. C. Democratização da escola pública: a pedagogia crítico-social dos conteúdos. São Paulo: Edições Loyola, 1985.

SCHEERENS, J.; BOSKER, R. The foundations of educational effectiveness. New York: Pergamon, 1997.

SCHEERENS, J.; BRUMMELHIUS, A. C. A. Process indicators on the functioning of schools: results from an international survey. New York: Aera Annual Meeting, 1996.

WORTHEN, Blaine R.; SANDERS, James L.; FITZPATRICK, Jody R. Avaliação de programas: concepções e práticas. Tradução Dinah de Abreu Azevedo. São Paulo: Gente, 2004.

Recebido em: 06/10/2011

Aceito para publicação em: 01/10/2012 